\title{
Determinants of self-rated health among an older Tibetan population in a Chinese plateau area: analysis based on the conceptual framework for determinants of health
}

Yajie $\mathrm{Li}^{1 \dagger}$, Qucuo Nima ${ }^{1 \dagger}$, Bin Yu², Xiong Xiao ${ }^{3}$, Peibin Zeng ${ }^{3}$, Deji Suolang ${ }^{1}$, Ruifeng He ${ }^{1}$, Zhuoga Ciren ${ }^{1}$, Pingcuo Wangqing ${ }^{1}$, Ciren Laba', Yangzong Silang ${ }^{1}$, Ling Song ${ }^{1}$, Yixi Kangzhu ${ }^{1}$ and Jingzhong Li $i^{*}$

\begin{abstract}
Background: Self-rated health (SRH) has been frequently used in population health surveys. However, most of these studies only focus on specific factors that might directly affect SRH, so only partial or confounding information about the determinants of SRH is potentially obtained. Conducted in an older Tibetan population in a Chinese plateau area, the aim of our study is to assess interrelationships between various factors affecting SRH based on the conceptual framework for determinants of health.

Methods: Between May 2018 and September 2019, 2707 Tibetans aged 50 years or older were recruited as part of the China Multi-Ethnic Cohort Study (CMEC) from the Chengguan District of Lhasa city in Tibet. The information included SRH and variables based on the conceptual framework for determinants of health (i.e., socioeconomic status, health behaviors, physical health, mental health, and chronic diseases). Structural equation modeling (SEM) was used to estimate the direct and indirect effects of multiple factors in the conceptual framework.

Results: Among all participants, 5.54\% rated their health excellent, $51.16 \%$ very good, $33.58 \%$ good, $9.12 \%$ fairly poor and $0.59 \%$ poor. Physical health $(\beta=-0.23, P<0.001)$, health behaviors $(\beta=-0.44, P<0.001)$, socioeconomic status $(\beta=-0.29, P<0.001)$, chronic diseases $(\beta=-0.32, P<0.001)$ and gender $(\beta=0.19, P<0.001)$ were directly associated with SRH. Socioeconomic status, physical health and gender affected SRH both directly and indirectly. In addition, there are potential complete mediator effects in which age and mental health affect SRH through mediators, such as physical health, health behaviors and chronic diseases.
\end{abstract}

Conclusions: The findings suggested that interventions targeting behavioral changes, health and chronic disease management should be attached to improve SRH among older populations in plateau areas without ignoring gender and socioeconomic disparities.

Keywords: Self-rated health, Social determinants of health, Plateau area, Older people

\footnotetext{
* Correspondence: 13908996200@139.com

${ }^{\dagger}$ Yajie Li and Qucuo Nima contributed equally to this work.

${ }^{1}$ Tibet Center for Disease Control and Prevention, Lhasa, China

Full list of author information is available at the end of the article
}

(c) The Author(s). 2021 Open Access This article is licensed under a Creative Commons Attribution 4.0 International License, which permits use, sharing, adaptation, distribution and reproduction in any medium or format, as long as you give appropriate credit to the original author(s) and the source, provide a link to the Creative Commons licence, and indicate if changes were made. The images or other third party material in this article are included in the article's Creative Commons licence, unless indicated otherwise in a credit line to the material. If material is not included in the article's Creative Commons licence and your intended use is not permitted by statutory regulation or exceeds the permitted use, you will need to obtain permission directly from the copyright holder. To view a copy of this licence, visit http://creativecommons.org/licenses/by/4.0/ The Creative Commons Public Domain Dedication waiver (http://creativecommons.org/publicdomain/zero/1.0/) applies to the data made available in this article, unless otherwise stated in a credit line to the data. 


\section{Background}

Self-rated health (SRH), which is generally evaluated based on a simple question of "How do you think of your present health?" [1], refers to an individual's expectation and evaluation of health status based on their subjective feelings and objective health information from physical, psychological and social adaptation [2]. Since the 1960s, SRH has been widely used to measure health inequalities in public health research for easy data collection and low costs $[3,4]$. As independent predictors for certain health outcomes (e.g., all-cause mortality, disease-specific mortality, morbidity and health service utilization) [5-8], SRH involves a large scope of health issues related to social, economic, behavioral, and psychological factors $[9,10]$. Currently, SRH is increasingly used to evaluate and monitor individual and population health status, similar to the predisease warning sign.

Previous studies have found that physical activity, drinking, tobacco use, chronic diseases, functional status, and psychosocial symptoms exhibited a significant association with SRH [11-13]. Although a large number of studies in Western countries have focused on SRH in recent years, most studies in this field only focus on specific factors affecting SRH and rarely consider that many of these factors have complex interrelationships that direct or indirect affect SRH $[9,14]$. To completely understand SRH, an in-depth exploration of the structure of SRH is required to clarify which factors are not only directly but also indirectly related to it. However, only a few studies have investigated the direct and indirect associations of health-related factors, chronic diseases, or psychological health with SRH $[15,16]$. There is still limited understanding of the factors that individuals refer to in assessing their health and how they act and interact to influence the final assessment. Investigations need to concomitantly assess the factors associated with $\mathrm{SRH}$. Currently, the conceptual framework for determinants of health has been developed to represent complex networks of casual pathways through which social factors interact with an individual's health risk and protective factors throughout the life course. As a comprehensive model comprising multidimensional variables, the conceptual framework for determinants of health might be helpful to estimate the factors associated with SRH with the presentation of direct and indirect relation paths.

In China, SRH was included in the national population survey data for the first time in 2003 with approximately 94.2\% of the population rating their health as 'very good' 'good' or 'fair' [17]. China, which has the largest number of older people, has entered a period of population aging since 2000. By the end of 2017, the number of older people aged 60 years and older reached 240.90 million, accounting for $17.3 \%$ of the total population [18]. The concept of healthy aging has become a global health strategy in response to population aging [19]. As physical function declines with age, older people are more likely to suffer from health problems (e.g., chronic diseases, depression, and disability) compared with their younger counterparts and are facing serious health care challenges [20-22]. Therefore, there is a need to better understand the most significant health aspects in older people and how SRH is structured among them. However, there have been limited studies about the influential factors of SRH among the Chinese aging population.

The Tibetan population, the majority of whom live in the Chinese plateau area, includes a large number of older people suffering from more adverse health outcomes and diseases, such as hypertension [23] and obesity [24], compared with the non-Tibetan population. As a study conducted in China found that the overall health status of the residents in the Tibet Autonomous Region is worse than that of other provinces in China [25]. The $\mathrm{SRH}$ of this vulnerable population is of concern. In addition, some special environmental factors, genetic factors, lifestyle, and health outcomes [26] may affect SRH. In such a scenario, it is crucial to better identify the multiple dimensions contributing to SRH.

To better understand the influencing factors of SRH in older Tibetan people in a Chinese plateau area, we aimed to reconstruct the system of relations connecting the different factors that affect SRH based on the conceptual framework for determinants of health. Most of the studies in this field only involve specific factors that might directly affect SRH; thus, only partial or confounded information about the determinants of elderly health can be obtained. Investigations in our study assess interrelationships between various factors affecting SRH and the direct or indirect effects of each factor on SRH within the conceptual framework. These evidence-based results might be helpful to implement appropriate public health policies and programs to improve the overall health of the population.

\section{Materials and methods Study design}

This cross-sectional study is part of and based on the baseline of the China Multi-Ethnic Cohort Study (CMEC), a community population-based study conducted between May 2018 and September 2019 in five provinces (Sichuan, Chongqing, Yunnan, Guizhou, and Tibet) of southwestern China. Detailed information about the CMEC study rationale, design, survey methods, and participant characteristics was reported previously [27]. The data used in the study are from the area of Chengguan District, Lhasa city, the capital of the Tibetan autonomous region in China. Lhasa is located in the middle of the Tibetan Plateau with an average 
elevation of $3650 \mathrm{~m}$, making it one of the highest cities in the world. In 2017, Chengguan District had a population of 215,804 inhabitants living on 12 streets. In addition, there were 31 ethnic groups (e.g., Tibetan nationality, Han nationality, and Hui nationality), among which the Tibetan population accounted for $87 \%$.

\section{Sampling procedure}

A multistage cluster sampling method was used to recruit the study participants from the communitybased population. First, we chose the Chengguan district of Lhasa in Tibet, which had the largest population density and convenient transportation, as the project site to facilitate the follow-up and management of the cohort population. Second, five out of the 12 streets were selected randomly, namely, Caigongtang Street, Niangre Street, Duodi Street, Najin Street, and Jinzhu West Road Street. Finally, all participants who met the inclusion criteria in the selected streets were invited to participate. The inclusion criteria were as follows: 1) Tibetan nationality; 2) living in the region for three generations or more; and 3) aged 30 or older. Those study participants who were not able to provide a unique national identification card, could not communicate independently and refused to comply with the requirements of the study were excluded from the study.

\section{Data collection}

Data were collected via electronic questionnaires and medical examinations. The questionnaire was developed from the Kadoorie Study of Chronic Disease in China [28], chronic diseases and nutrition surveillance among Chinese adults [29], and other relevant literature [30] based on the study objectives. The information was collected through face-to-face interviews by 35 well-trained interviewers recruited from Tibetan university students with medical backgrounds.

Of 7441 participants, 4550 were aged under 50 years old, and 184 were excluded due to missing records on height, weight, or other important research variables. Finally, a total of 2707 participants were included and analyzed in this study.

\section{Measurement}

\section{Self-rated health}

The question used for self-rated health was "How do you think of your present health?" The respondents were asked to provide an overall assessment of their current health status. The response options were (a) very good (5-score), (b) fairly good (4-score), (c) average (3-score), (d) fairly poor (2-score), and (e) poor (1-score).

\section{Demographics}

Demographics included age (classified as 50-54, 55-59, and $60+$ ), gender (male vs. female), and marital status (cohabited [married or not] vs. did not cohabit [(Separated/divorced/widowed and never married)]).

\section{Socioeconomic status}

Socioeconomic status included educational attainment, employment, household annual income, registered permanent residence, and medical insurance. Educational attainment was classified into three groups: 1 (middle school and above), 2 (elementary school) and 3 (no formal education). Employment was classified into two groups: 1 (employed) and 2 (unemployed). Household annual income was classified into four groups: $1(\geq 60$, 000 CNY), 2 (20000-59,999 CNY), 3 (12000-19,999 $\mathrm{CNY})$ and $4(\leq 12,000 \mathrm{CNY})$. Registered permanent residence was classified into three groups: 1 (unified household), 2 (urban) and 3 (rural). Medical insurance was coded according to the level of security covered by the government-funded social health insurance program: 1, Medical Insurance for Urban Employees (MIUE); 2, Medical Insurance for Urban Residents (MIUR); 3, New Rural Cooperative Medical Scheme (NCMS); 4, Medical Insurance for Rural Residents (MIRR); and 5, no medical insurance coverage.

\section{Health behaviors}

Health behaviors included smoking, alcohol consumption, quality of nighttime sleep, sleep duration, and physical activity. Smoking was assessed by an item that asked, "Do you smoke?". There are three response options, namely, never (smoked less than 100 cigarettes during their life), ever (not currently smoking), and current (smoking at least one cigarette or less than one cigarette a day) [31]. Alcohol consumption was assessed with the frequency choice of "none", "once a week or less", or "more than once a week". Quality of nighttime sleep score was generated by collating responses from the following four items: (a) "It took more than half an hour to fall asleep, at least three days a week" (b) "I woke up very early and had been difficult to fall asleep again, at least three days a week" (c) "I took sleeping pills, at least one day a week" and (d) "I had difficulty concentrating when working, eating or talking in the daytime because of poor sleep last night, at least three days a week." Each of the four items included no or yes response options, which were given a corresponding value of zero or one, respectively. Responses from each item were summed to calculate the overall quality of the nighttime sleep score. A higher total score indicates poor quality of nighttime sleep. Sleep duration was assessed by an item that asked, "On average, how many hours do you usually sleep per night last month?". According to 
previous studies [32], 7-8 h/night was considered adequate sleep duration for older people. In addition, short sleep and long sleep duration were associated with poor SRH, with short sleep seeming to affect SRH more seriously [33, 34]. Thus, participants' responses were scored as 1 ( $7-8 \mathrm{~h} /$ night), $2(>9 \mathrm{~h} /$ night $)$, and $3(<7 \mathrm{~h} /$ night $)$. Physical activity considered participants' job-related physical activity, transportation physical activity, leisuretime physical activity, and housework and was divided into two groups based on the median metabolic equivalent for task (MET).

\section{Mental health}

Mental health was assessed using two variables: depression and anxiety. Depression was measured as a continuous variable using the Patient Health Questionnaire-2 (PHQ-2) [35], namely, (a) "Little interest or pleasure in doing things" and (b) "Feeling down, depressed, or hopeless". The PHQ-2, a short version of the PHQ-9, is composed of the first two items of the PHQ-9 [36]. The internal reliability of the PHQ-2 has been reported at Cronbach's $\alpha=0.76$ in older Chinese rural people [37]. The reliability of vitality in this study (Cronbach's $\alpha=$ 0.76) was similar to that of this report. Anxiety was measured as a continuous variable using the 2-item Generalized Anxiety Disorder Questionnaire (GAD-2) [38], namely, (a) "Not being able to stop or control worrying" and (b) "Feeling nervous, anxious, or on edge". The GAD-2 is an abridged version of the tool that is composed of the first two items of the GAD-7 [39]. There is evidence demonstrating good reliability and validity of the PHQ-2 (Cronbach's $\alpha=0.82$ ) [40]. The reliability of vitality in our study (Cronbach's $\alpha=0.72$ ) was comparatively lower compared with that in these reports.

The score of each item ranges from 0 (not at all) to 3 (nearly every day). The total score is obtained by the simple addition of item scores and ranges between 0 and 6. A higher total score indicates more mental health problems.

\section{Physical health}

Mobility, pain, activities of daily living (ADL), and selfcare were used as measures for physical health. Mobility was based on the question "Is it difficult for you to get around?". Pain was based on the question "Do you have any pain or discomfort today?". ADL was based on the question "Do you have any difficulties with your daily activities today?" Self-care was based on the question "Do you have any trouble taking care of yourself today?". For each item, the options were (a) "none", (b) "a little bit", (c) "moderate", (d) "serious", and (e) "very serious". The score of each item ranges from 0 (none) to 5 (very serious).

\section{Chronic diseases}

Four chronic diseases were included in the study: obesity, hypertension, hyperlipidemia, and diabetes. Height and weight were collected during the medical examination, and body mass index (BMI) was calculated as weight in kilograms per height in squared meters. Obesity was defined as having a $\mathrm{BMI} \geq 28.00$ according to China's BMI criterion [41]. For hypertension, hyperlipidemia, and diabetes, participants were asked whether they had been diagnosed with these diseases by a doctor.

\section{Statistical analysis}

The conceptual framework for determinants of health [42], which was developed by the commission on social determinants in 2008, consists of the following three key components: (a) the socioeconomic and political environment; (b) the individual socioeconomic status, including the status and degree of social stratification by gender and race; and (c) the intermediate determinants of health, including the differential material environment, social psychology, behavioral factors and health service status of different populations.

According to the conceptual framework for determinants of health, we built a hypothesized model with measurement SRH as the dependent variable. To concomitantly explore factors associated with SRH yet retain a parsimonious model, we delimited the study by restricting the explanatory variables to the following: socioeconomic status (educational attainment, employment, household annual income, medical insurance, and registered permanent residence), health behaviors (smoking, alcohol consumption, sleep duration, physical activity and quality of nighttime sleep), physical health (anxiety and depression), mental health (mobility, pain, take care of myself, and activities of daily living), and chronic diseases (hypertension, diabetes, hyperlipidemia and obesity). The Kruskal-Wallis test was used to compare the differences in SRH between groups. The total scores of anxiety and depression were not normally distributed, and the differences in these variables and SRH were tested using the MannWhitney U-test. Structural equation modeling (SEM) was used to estimate the model fitting degree of the data, and the direct and indirect effects of multiple factors in the hypothesis model were analyzed. Demographics (age and gender) are inevitably exogenous and can only be affected by other factors rather than by themselves.

For all factors included in the SEM, higher scores indicate older age, male gender, lower educational attainment, unemployment, lower household annual income, lower entitlement insurance schemes, rural registered permanent residence, having more physical health problems, never smoking or drinking alcohol, poor quality of 
nighttime sleep, having more mental health problems, and having been diagnosed with chronic diseases.

Multiple indicators were used to evaluate the fit of the model, namely, relative $\chi^{2}(\mathrm{CMIN} / \mathrm{DF})$ and baseline comparison fit indices of NFI, RFI, IFI, TLI, CFI, RMR and RMSEA [15]. All analyses were performed using SPSS (IBM, Armonk, NY, USA) and AMOS 21.0 statistical software (IBM, Armonk, NY, USA). The association was considered to be statistically significant if the 2sided $P$-value was less than 0.05 .

\section{Results}

\section{Characteristics of participants}

A total of 2707 participants were analyzed in this study, and $60.02 \%$ of them were female. The mean age of the participants was $58.8 \pm 6.8$ years, ranging from 50 to 84 years old. The majority (87.44\%) of participants cohabited, and 1969 (72.24\%) were unemployed. Greater than half of the participants $(62.87 \%)$ had received no formal education; only $7.24 \%$ had completed middle school or above education. Their household annual income was distributed evenly across the four ranges. Participants were less likely to report smoking $(15.11 \%$ for the current smoker and $6.83 \%$ for ever smoker) and drinking (17.33\% drank less than once a week and $8.79 \%$ drank more than once a week). The median level of physical activity was $18.9 \mathrm{MET} /$ day. Most (65.87\%) participants reported an adequate sleep duration between 7 and $8 \mathrm{~h}$. The self-reported prevalence rates of chronic diseases ranged from high to low followed by hypertension (31.29\%), hyperlipidemia (25.60\%), obesity (19.95\%) and diabetes (3.58\%). The median scores of nighttime sleep quality, anxiety, and depression were $0(0,1), 0(0,1)$, and $0(0,1)$, respectively (Table 1$)$.

\section{Studied variables associated with self-rated health}

Among all participants, 5.54\% rated their health excellent, $51.16 \%$ very good, $33.58 \%$ good, $9.12 \%$ fairly poor and $0.59 \%$ poor. Sex, age, marital status, education, household annual income, employment, registered permanent residence, medical insurance, smoking, alcohol consumption, sleep duration, quality of nighttime sleep, hypertension, hyperlipidemia, obesity, and diabetes were associated with SRH (Table 1).

\section{Effect of studied variables on self-rated health}

The final structural model (Fig. 1) described the upstream associations of demographics, socioeconomic status, health behaviors, physical health, mental health and chronic diseases on SRH as well as their interactions, with adequate model fit.

Based on standardized path weight coefficients ( $\beta$ 's), physical health $(\beta=-0.23, P<0.001)$, health behaviors $(\beta=-0.44, P<0.001)$, socioeconomic status $(\beta=-0.29, P<0.001)$, chronic diseases $(\beta=$ - 0.32, $P<0.001)$ and gender $(\beta=0.19, P<0.001)$ were directly associated with SRH among older Tibetan people. The SRH decreased by $0.23,0.44,0.29$ and 0.32 units for every unit change in physical health, health behaviors, socioeconomic status and chronic diseases. The SRH of men was 0.19 units higher than that of women. This finding indicates that participants with higher scores on physical health reported poor SRH, and participants who had been diagnosed with hypertension, diabetes, hyperlipidemia or obesity reported poor SRH. Women seem to be more likely to rate their health as poorer than men.

Socioeconomic status exhibited a modest association with SRH. This finding indicates that lower educational attainment, unemployment, lower household annual income, and lower levels of medical insurance entitlement were risk factors for SRH.

Health behaviors were one of the strongest factors associated with SRH. This finding indicated that participants who do not drink alcohol perceived poorer health than those who drink occasionally or frequently. Nonsmokers reported poorer SRH than smokers or current smokers. High scores in the quality of nighttime sleep and short sleep duration were negatively associated with SRH.

\section{Estimates of direct and indirect effects}

The mediating effect was tested with bias-corrected bootstrapping. The method of repeated random sampling was used to extract 2000 samples from the original data, and an approximate sampling distribution was generated. The confidence interval of the mediating effect of $95 \%$ was estimated by the 2.5 percentile and 97.5 percentile.

Table 2 indicates the total effect of all latent variables on SRH. Overall, health behavior had the greatest total effect on SRH followed by chronic diseases and mental health with standardized regression coefficients of $-0.522,-0.323$ and -0.320 , respectively. Socioeconomic status, physical health and gender affected SRH both directly and indirectly; however, the total effect of socioeconomic characteristics on SRH was not statistically significant. The direct effect of physical health on SRH was much greater than its indirect effect. The likelihood of physical health influencing SRH via mediators (such as chronic diseases) was minimal given that its indirect effect was close to zero. The indirect effect of gender on SRH was greater than its direct effect. There are potential complete mediator effects in which age and mental health affect SRH through mediators, such as physical health, health behaviors and chronic diseases. 
Table 1 Characteristics of participants and self-rated health $(n=2707)$

\begin{tabular}{|c|c|c|c|c|c|c|c|}
\hline \multirow[t]{2}{*}{ Characteristics of participants } & \multirow[t]{2}{*}{ Full sample } & \multicolumn{5}{|c|}{ Self-rated health status } & \multirow[t]{2}{*}{$P$-value } \\
\hline & & Poor & Fair & Good & Very good & Excellent & \\
\hline \multicolumn{8}{|l|}{ Demographics } \\
\hline Gender $^{a}$ & & & & & & & $<0.001$ \\
\hline Male & $1066(39.38)$ & $6(0.56)$ & $62(5.82)$ & $299(28.05)$ & $61(57.41)$ & $87(8.16)$ & \\
\hline Female & $1641(60.62)$ & $10(0.61)$ & $185(11.27)$ & $610(37.17)$ & $773(47.11)$ & $63(3.84)$ & \\
\hline Age $^{a}$ & & & & & & & $<0.001$ \\
\hline $50-54$ & $889(32.84)$ & $5(0.56)$ & $58(6.52)$ & $273(30.71)$ & $491(55.23)$ & $62(6.97)$ & \\
\hline $55-59$ & $783(28.93)$ & $7(0.89)$ & $61(7.79)$ & $278(35.50)$ & $384(49.04)$ & $53(6.77)$ & \\
\hline$\geq 60$ & $1035(38.23)$ & $4(0.39)$ & $128(12.37)$ & $358(34.58)$ & $510(49.28)$ & $35(3.38)$ & \\
\hline Socioeconomic status Education ${ }^{a}$ & & & & & & & $<0.001$ \\
\hline No formal education & $1702(62.87)$ & $14(0.82)$ & $190(11.16)$ & $615(36.13)$ & $807(47.41)$ & $76(4.47)$ & \\
\hline Elementary school & 809 (29.89) & $2(0.25)$ & $46(5.69)$ & $237(29.30)$ & $467(57.73)$ & $57(7.05)$ & \\
\hline Middle school and above & $196(7.24)$ & $0(0)$ & $11(5.61)$ & $57(29.08)$ & $111(56.63)$ & $17(8.67)$ & \\
\hline Household annual income ${ }^{a}$ & & & & & & & $<0.010$ \\
\hline$\leq 12,000 \mathrm{CNY}$ & $680(25.12)$ & $6(0.88)$ & $83(12.21)$ & $250(36.76)$ & $304(44.71)$ & $37(5.44)$ & \\
\hline $12,000-19,999$ CNY & $715(26.41)$ & $8(1.12)$ & $56(7.83)$ & $228(31.89)$ & $384(53.71)$ & $39(5.45)$ & \\
\hline 20,000-59,999 CNY & $856(31.62)$ & $1(0.12)$ & $80(9.35)$ & $278(32.48)$ & $443(51.75)$ & $54(6.31)$ & \\
\hline$\geq 60,000 \mathrm{CNY}$ & $456(16.85)$ & $1(0.22)$ & $28(6.14)$ & $153(33.55)$ & $254(55.70)$ & $20(4.39)$ & \\
\hline Employment ${ }^{a}$ & & & & & & & $<0.001$ \\
\hline Employed & $738(27.26)$ & $10(1.36)$ & $50(6.78)$ & $208(28.18)$ & $406(55.01)$ & $64(8.67)$ & \\
\hline Unemployed & $1969(72.74)$ & $6(0.30)$ & $197(10.01)$ & $701(35.60)$ & 979 (49.72) & $86(4.37)$ & \\
\hline Registered permanent residence ${ }^{a}$ & & & & & & & $<0.001$ \\
\hline Rural & $2253(83.23)$ & $13(0.58)$ & 219 (9.72) & $726(32.22)$ & $1159(51.44)$ & $136(6.04)$ & \\
\hline Urban & $401(14.81)$ & $2(0.50)$ & $19(4.74)$ & 155 (38.65) & $211(52.62)$ & $14(3.49)$ & \\
\hline Unified household & $53(1.96)$ & $1(1.89)$ & $9(16.98)$ & $28(52.83)$ & $15(28.30)$ & $0(0)$ & \\
\hline Medical insurance ${ }^{a}$ & & & & & & & $<0.001$ \\
\hline MIUE & $243(8.98)$ & $1(0.41)$ & $8(3.29)$ & $83(34.16)$ & $142(58.44)$ & $9(3.70)$ & \\
\hline MIUR & $358(13.22)$ & $1(0.28)$ & $27(7.54)$ & $143(39.94)$ & $167(46.65)$ & $20(5.59)$ & \\
\hline NCMS & $1198(44.26)$ & $2(0.17)$ & $78(6.51)$ & 399 (33.30) & $629(52.50)$ & $90(7.51)$ & \\
\hline MIRR & $848(31.33)$ & $12(1.42)$ & $133(15.68)$ & $263(31.01)$ & $410(48.35)$ & $30(3.54)$ & \\
\hline No medical insurance & $60(2.22)$ & $0(0)$ & $1(1.67)$ & $21(35.00)$ & $37(61.67)$ & $1(1.67)$ & \\
\hline \multicolumn{8}{|l|}{ Health behaviors } \\
\hline Smoking ${ }^{a}$ & & & & & & & $<0.001$ \\
\hline Never & $2113(78.06)$ & $15(0.71)$ & $208(9.84)$ & $750(35.49)$ & $1036(49.03)$ & $104(4.92)$ & \\
\hline Ever & $185(6.83)$ & $1(0.54)$ & $18(9.73)$ & $56(30.27)$ & $99(53.51)$ & $11(5.95)$ & \\
\hline Current & 409 (15.11) & $0(0)$ & $21(5.13)$ & $103(25.18)$ & $250(61.12)$ & $35(8.56)$ & \\
\hline Alcohol consumption ${ }^{a}$ & & & & & & & $<0.001$ \\
\hline No & $2000(73.88)$ & $15(0.75)$ & $216(10.80)$ & $693(34.65)$ & $978(48.90)$ & $98(4.90)$ & \\
\hline Occasionally (less than once a week) & $469(17.33)$ & $1(0.21)$ & $25(5.33)$ & $157(33.48)$ & $254(54.16)$ & $32(6.82)$ & \\
\hline Frequently (more than once a week) & $238(8.79)$ & $0(0)$ & $6(2.52)$ & $59(24.79)$ & $153(64.29)$ & $20(8.40)$ & \\
\hline Physical activity ${ }^{a}$ & & & & & & & $>0.050$ \\
\hline Low ( $\leq 18.9$ MET/day) & $1353(49.98)$ & $14(1.03)$ & $123(9.09)$ & $476(35.18)$ & $656(48.48)$ & $84(6.21)$ & \\
\hline High (> 18.9 MET/day) & $1354(50.02)$ & $2(0.15)$ & $124(9.16)$ & $433(31.98)$ & 729 (53.84) & $66(4.87)$ & \\
\hline Sleep duration (per night) ${ }^{a}$ & & & & & & & $<0.010$ \\
\hline
\end{tabular}


Table 1 Characteristics of participants and self-rated health $(n=2707)$ (Continued)

\begin{tabular}{|c|c|c|c|c|c|c|c|}
\hline \multirow[t]{2}{*}{ Characteristics of participants } & \multirow[t]{2}{*}{ Full sample } & \multicolumn{5}{|c|}{ Self-rated health status } & \multirow[t]{2}{*}{$P$-value } \\
\hline & & Poor & Fair & Good & Very good & Excellent & \\
\hline$<7 \mathrm{~h}$ & $184(6.80)$ & $4(2.17)$ & $27(14.67)$ & $65(35.33)$ & $81(44.02)$ & $7(3.80)$ & \\
\hline $7 \mathrm{~h}-8 \mathrm{~h}$ & $1783(65.87)$ & $6(0.34)$ & $149(5.50)$ & $592(33.20)$ & $926(51.93)$ & $110(6.17)$ & \\
\hline$>8 \mathrm{~h}$ & $740(27.34)$ & $6(0.81)$ & $71(9.59)$ & $252(34.05)$ & $378(51.08)$ & $33(4.46)$ & \\
\hline Quality of nighttime sleep b & $0(0,1.0)$ & $1.5(0,2.0)$ & $1.0(0,2.0)$ & $0(0,2.0)$ & $0(0,1.0)$ & $0(0,1.0)$ & $<0.001$ \\
\hline \multicolumn{8}{|l|}{ Chronic diseases } \\
\hline Obesity $^{a}$ & & & & & & & $>0.050$ \\
\hline No & $2167(80.05)$ & $14(0.65)$ & $207(9.55)$ & 717 (33.09) & $1104(50.95)$ & $125(5.77)$ & \\
\hline Yes & $540(19.95)$ & $2(0.37)$ & $40(7.41)$ & $192(35.56)$ & $281(52.04)$ & $25(4.63)$ & \\
\hline Hypertension ${ }^{a}$ & & & & & & & $<0.001$ \\
\hline No & $1860(68.71)$ & $9(0.48)$ & $134(7.20)$ & $590(31.72)$ & $1006(54.09)$ & $121(6.51)$ & \\
\hline Yes & $847(31.29)$ & $7(0.83)$ & $113(13.34)$ & $319(37.66)$ & 379 (44.75) & $29(3.42)$ & \\
\hline Diabetes $^{a}$ & & & & & & & $<0.010$ \\
\hline No & $2610(96.42)$ & $14(0.54)$ & $234(8.96)$ & 867 (33.22) & $1353(51.84)$ & $142(5.44)$ & \\
\hline Yes & 97 (3.58) & $2(2.06)$ & $13(13.40)$ & $42(43.30)$ & 32 (32.99) & $8(8.25)$ & \\
\hline Hyperlipidemia $^{a}$ & & & & & & & $<0.001$ \\
\hline No & $2014(74.40)$ & $8(0.40)$ & $154(7.65)$ & $653(32.42)$ & $1083(53.77)$ & $116(5.76)$ & \\
\hline Yes & $693(25.60)$ & $8(1.15)$ & $93(13.42)$ & 256 (36.94) & 302 (43.58) & $34(4.91)$ & \\
\hline \multicolumn{8}{|l|}{ Mental health } \\
\hline Anxiety ${ }^{b}$ & $0(0,1.0)$ & $1.0(0,2.0)$ & $1.0(0,2.0)$ & $1.0(0,2.0)$ & $0(0,1.0)$ & $0(0,0)$ & $<0.001$ \\
\hline Depression ${ }^{b}$ & $0(0,1.0)$ & $2.0(0,2.0)$ & $2.0(0,2.0)$ & $0(0,2.0)$ & $0(0,1.0)$ & $0(0,0)$ & $<0.001$ \\
\hline
\end{tabular}

\section{Discussion}

This study used SEM to systematically examine the factors associated with SRH. By including multiple variables into one conceptual model and analyzing them simultaneously, the study is unique in its ability to describe a complex network. All five latent variables based on the conceptual framework for determining health (i.e., socioeconomic status, health behaviors, physical health, mental health, and chronic diseases) were predictors of SRH.

The findings of this study demonstrate the association between socioeconomic status and SRH. First, previous studies have identified lower levels of education, lower income, and unemployment as important risk factors for SRH $[43,44]$, and the same conclusion was echoed in our study. Second, we found that lower levels of medical insurance entitlement were risk factors for SRH, which is similar to findings from other studies $[45,46]$. A lack of medical insurance limits access to preventive services [47]. It is important to acknowledge that health insurance interventions have the potential to improve health outcomes, such as mental health and SRH [48]. In addition, China's social health insurance schemes are linked to registered permanent residence and occupation. The medical insurance for urban residents and formal employees has better social security benefits. The link between medical insurance and SRH partially reflects occupational and urban-rural disparities. Third, this study found that registered permanent residence status is the most important socioeconomic factor affecting SRH. Under the background of the urban-rural dual structure in China [49], registered permanent residence reflects the socioeconomic status of residents. Registered permanent residence status has been widely accepted as a factor associated with many diseases [50], which obviously affects SRH [51].

Our study assessed the relationship between SRH and four health behaviors (smoking, alcohol consumption, sleep duration, and quality of nighttime sleep) simultaneously. The importance of health behaviors on individual health has been widely accepted [52]. Consistent with previous research [53], the findings of this study confirmed that poor quality of nighttime sleep and short sleep duration were negatively associated with SRH. This finding highlights the value of healthy sleep hygiene in older people. In addition, we found that drinking seemed to be a protective factor for SRH. This result is consistent with findings of the English Longitudinal Study of Aging, which reported that nondrinkers reported a significantly increased rate of self-rated poor health than those who drank occasionally [54]. However, another 


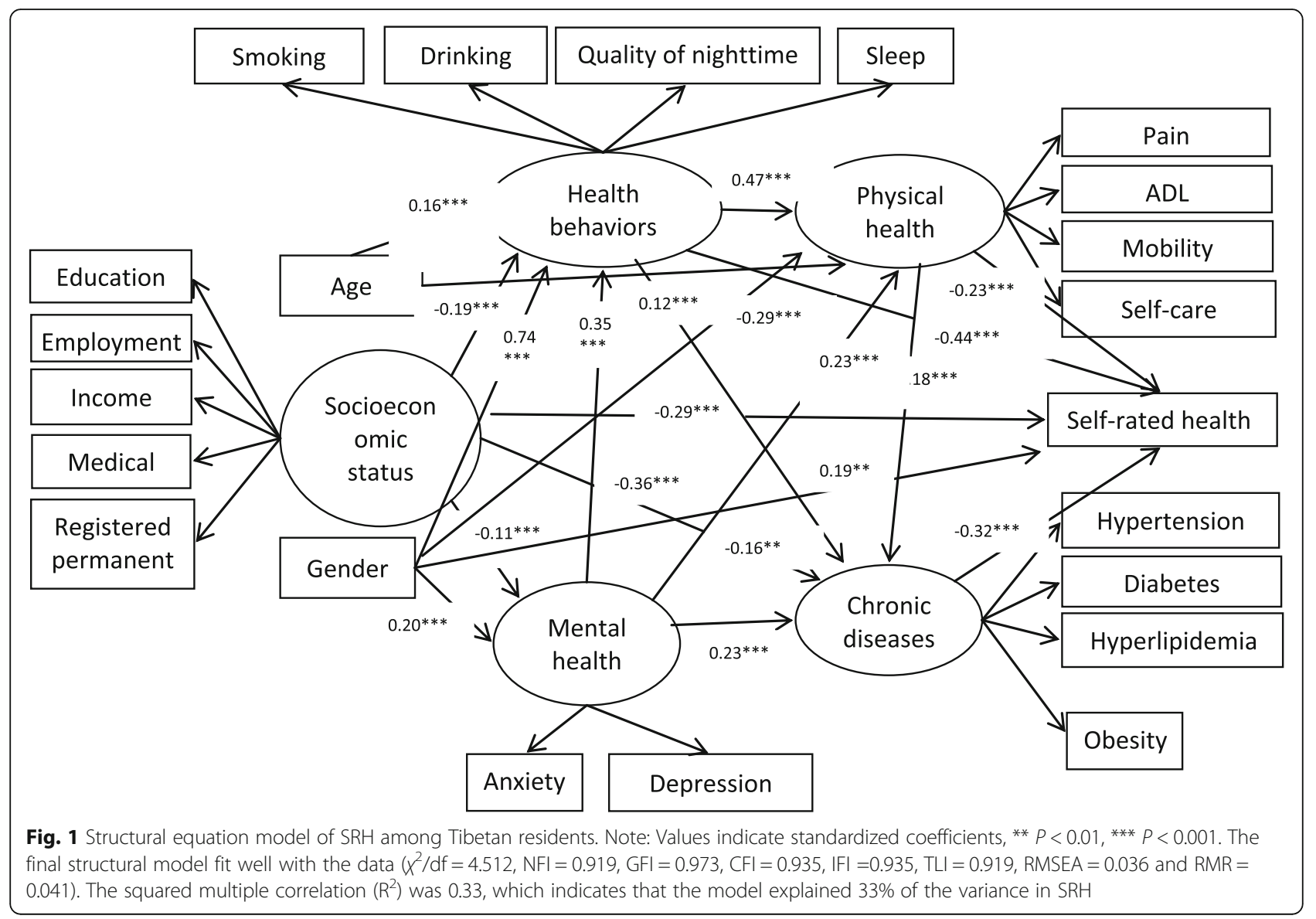

study conducted in the US revealed a negative association between alcohol consumption and SRH [14]. The difference with respect to this study may be related to the unique customs of the minorities. For smoking behavior, as noted in previous studies, the prevalence of poor SRH was highest among nonsmokers $[55,56]$. Our results differ from previous findings, indicating that nonsmokers reported poorer SRH than smokers or current smokers. Various studies demonstrated that smokers are less concerned about the future consequences of their health behaviors than nonsmokers [57]. Our participants

Table 2 Direct and indirect effects of variables on self-rated health $(\mathrm{SRH})$

\begin{tabular}{llll}
\hline Latent Variable & Direct Effect & Indirect Effect & Total Effect \\
\hline Socioeconomic status & $-0.294^{* * *}$ & $0.252^{* * *}$ & -0.042 \\
Health behaviors & $-0.439^{* * *}$ & -0.083 & $-0.522^{* *}$ \\
Physical health & $-0.230^{* * *}$ & $-0.059^{* * *}$ & $-0.289^{* * *}$ \\
Mental health & 0 & $-0.320^{* * *}$ & $-0.320^{* * *}$ \\
Chronic diseases & $-0.323^{* * *}$ & 0 & $-0.323^{* * *}$ \\
Gender & $0.194^{*}$ & $-0.366^{* * *}$ & $-0.172^{* * *}$ \\
Age & 0 & $-0.119^{* * *}$ & $-0.119^{* * *}$ \\
\hline
\end{tabular}

${ }^{*} p<0.05,{ }^{* *} p<0.01,{ }^{* * *} p<0.001$ were mainly older people with low education levels who may have a worse understanding of the dangers of smoking. Health behaviors not only had a large direct effect but also served as an important bridge to strengthen the effect of socioeconomic status and mental health on $\mathrm{SRH}$. These findings suggest that the associations between drinking, alcohol consumption and SRH may show different directions due to the influence of cultural factors and education level. Physical activity had no significant effect on SRH. It is well documented that physical activity has an important impact on health outcomes [58]. In this study, a possible explanation for the nonsignificant effect may be that participants generally reported lower levels of physical activity (18.9 MET per day), which is substantially lower than a previous study on older people in Chinese nonethnic minority areas [59].

We found that higher scores of physical health were associated with poorer SRH. Given that SRH is based on people's subjective feelings of their physical health information [60], older people with poor physical health may be more likely to report poor SRH. We found that participants who had been diagnosed with chronic diseases were more likely to rate their health as poor, which is 
consistent with previous findings [2, 51, 61]. Prevention interventions for chronic diseases should be enhanced at the community level, and standardized management of patients with chronic diseases should be strengthened to improve overall health.

Interestingly, some direct and indirect associations were noted among components of the model based on the conceptual framework for determinants of health, which are worthy of discussion. First, we found that the effects of physical health on SRH involved both direct and indirect effects, and physical health played an intermediary role in the associations among health behaviors, mental health and SRH. The importance of physical health in our SEM model suggests that the health status of older people should be considered. Second, this study found that mental health had no direct effect on SRH, but it had a strong indirect effect. Many studies have demonstrated the association between mental health and SRH $[62,63]$. Mental health was associated with socioeconomic status, health behaviors, physical health, chronic diseases, and gender in the model and can indirectly affect SRH through variables, such as healthy behaviors, physical health, and chronic diseases. Finally, our results confirmed that gender had a strong association with SRH, and gender was associated with mediating variables interacting with health behavior and health outcome variables in the model. Future research on SRH should not ignore the influence of gender differences.

The strength of this study is the simultaneous assessment of the association between many factors and SRH and the description of the complex interaction. These effects of factors can then be ranked according to their strength of association to identify priority areas for intervention. In addition, our participants were all Tibetans from a plateau area in China whose lifestyles and health conditions may be unique to other Chinese populations, yet remarkably little is known about these topics. We hope that the information can guide the local health intervention, such as prevention and control of chronic diseases.

There were several limitations in this study. First, the data we used were from a cross-sectional study and thus cannot allow one to infer causality. Second, the use of self-report data for some variables can introduce recall bias. For instance, sleep duration was self-reported, so it may not be exactly accurate. Third, the model presented in this study represents only a fraction of the overall impacts of SRH. For example, social networks demonstrate a unique positive association with SRH [64], and this was not assessed in this study given that no data on social networks were collected.

\section{Conclusion}

Based on the conceptual framework for determinants of health, this study first described the complex network of factors concomitantly associated with self-rated health (SRH) among the older population in a Chinese plateau area. Our findings suggested that interventions targeting behavioral changes, health and chronic disease management should be attached to improve SRH among older populations in the plateau area without ignoring gender differences and socioeconomic disparities. More studies of variables affecting SRH interactions based on the conceptual framework for determinants of health might be needed to provide information for targeted interventions of SRH improvement among other subgroups.

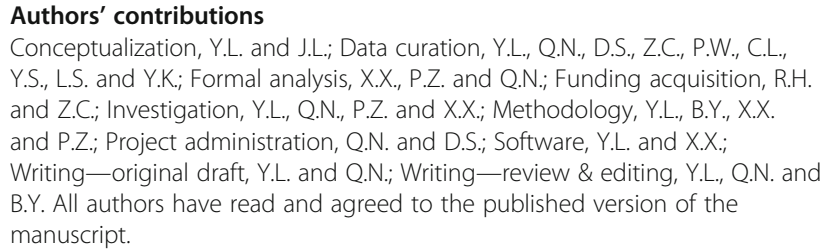

\section{Funding}

This work was supported by the National Key R\&D Program of China (Grant no: 2017YFC0907302 and 2017YFC0907300).

\section{Availability of data and materials}

The datasets used and analysed during the current study are available from the corresponding author on reasonable request.

\section{Ethics approval and consent to participate}

This study was approved by the ethics committee of Sichuan University (K2016038).

Informed consent was obtained from all participants, and all methods were performed in accordance with the relevant guidelines and regulations. The records of participants were anonymized and deidentified before analysis.

Consent for publication

Not applicable.

\section{Competing interests}

The authors declare no conflicts of interest.

\section{Author details}

${ }^{1}$ Tibet Center for Disease Control and Prevention, Lhasa, China. ${ }^{2}$ West China Second University Hospital of Sichuan University and Key Laboratory of Birth Defects and Related Diseases of Women and Children (Sichuan University), Ministry of Education, Chengdu, China. ${ }^{3}$ West China School of Public Health and West China Fourth Hospital, Sichuan University, Chengdu, China.

Received: 3 December 2020 Accepted: 21 January 2021

Published online: 11 March 2021

\section{References}

1. DeSalvo KB, Bloser N, Reynolds K, He J, Muntner P: Mortality prediction with a single general self-rated health question. J General Int Med. 2010;21(3): 267-75.

2. Golini N, Egidi V. The latent dimensions of poor self-rated health: how chronic diseases, functional and emotional dimensions interact influencing self-rated health in Italian elderly. Soc Indicators Res. 2016;128(1):321-39.

3. Bombak AE. Self-rated health and public health: a critical perspective. Front Public Health. 2013;1:15.

4. Maddox GL. Some correlates of differences in self-assessment of healthstatus among the elderly. J Gerontol. 1962;17(2):180-5. 
5. Shuko T, Soong-nang J, Shiho K, Ichiro K. Gender inequalities in poor selfrated health: cross-national comparison of South Korea and Japan. Soc Sci Med. 2020;252:112919.

6. DeSalvo KB, Jones TM, Peabody J, McDonald J, Fihn S, Fan V, He J, Muntner $P$. Health care expenditure prediction with a single item, self-rated health measure. Med Care. 2009:47(4):440-7.

7. Willerth M, Ahmed T, Phillips SP, Pérez-Zepeda MU, Zunzunegui MV, Auais $M$. The relationship between gender roles and self-rated health: a perspective from an international study. Arch Gerontol Geriatr. 2020;87: 103994.

8. Shiho K, Soong-nang J, Shuko T, KED, Ichiro K. Socioeconomic disparities in self-rated health in two East Asian countries: Comparative study between Japan and Korea. Soc Sci Med. 2020:253:112945.

9. Jonnalagadda SS, Diwan S. Health behaviors, chronic disease prevalence and self-rated health of older Asian Indian Immigrants in the U.S. J Immigrant Health. 2005;7(2):75-83.

10. Hanibuchi T, Nakaya T, Murata C. Socio-economic status and self-rated health in East Asia: a comparison of China, Japan, South Korea and Taiwan. Eur J Pub Health. 2012;22(1):47-52.

11. Haseen F, Adhikari R, Soonthorndhada K. Self-assessed health among Thai elderly. BioMed Central. 2010;10(1):30.

12. Khalaila RNR. Socioeconomic status, health behaviors, obesity and self-rated health among older Arabs in Israel. J Cross-Cultural Gerontol. 2017;32(1):115-30.

13. Mendoza-Romero D, Urbina A, Cristancho-Montenegro A, Rombaldi A. Impact of smoking and physical inactivity on self-rated health in women in Colombia. Prev Med Rep. 2019;16:100976.

14. Albqoor MA, Chen JL, Weiss S, Waters C, Choi J. Self-rated health of middle eastern immigrants in the US: a national study. Public Health. 2019;180:6473.

15. Craig BA, Morton DP, Morey PJ, Kent LM, Gane AB, Butler TL, Rankin PM, Price KR. The association between self-rated health and social environments, health behaviors and health outcomes: a structural equation analysis. BioMed Central. 2018;18(1):440.

16. Golini N, Egidi V. The latent dimensions of poor self-rated health: how chronic diseases, functional and emotional dimensions interact influencing self-rated health in Italian elderly. Soc Indic Res. 2015;128(1):321-39.

17. Bi Q, Hu J. Perceived health expectancy in China. Chinese J Health Stat. 2008;25(2):151-3.

18. Hegarty L, Murphy MH, Kirby K, Murtagh E, Mallett J, Mair JL. The influence of role models on the sedentary behaviour patterns of primary school-aged children and associations with psychosocial aspects of health. Int J Environ Res Public Health. 2020;17(15):5345.

19. Kalache A, Kickbusch IJWH. A global strategy for healthy ageing; 1997. p. 50.

20. Sun J, Lyu S, Zhao R. Socioeconomic inequality in health outcomes among the elderly: evidence from a cross-sectional study in China. Risk Manag Healthc Policy. 2020;13:397-407.

21. Tang S, Long C, Wang R, Liu Q, Feng D, Feng Z. Improving the utilization of essential public health services by Chinese elderly migrants: strategies and policy implication. Glob Health. 2020;10(1):010807.

22. Zhang Y, Zhou L, Liu S, Qiao Y, Wu Y, Ke C, Shen Y. Prevalence, correlates and outcomes of multimorbidity among the middle-aged and elderly: findings from the China health and retirement longitudinal study. Arch Gerontol Geriatr. 2020;90:104135.

23. Aryal N, Weatherall M, Bhatta YK, Mann S. Blood pressure and hypertension in adults permanently living at high altitude: a systematic review and metaanalysis. High Alt Med Biol. 2016;17(3):185-93.

24. Zheng CY, Wang ZW, Chen Z, Zhang LF, Wang X, Dong Y, Nie JY, Wang JL, Shao L, Tian Y. Association between the types of obesity and the 10-yearcoronary heart disease risk, in Tibet autonomous region and Xinjiang Uygur autonomous region. Zhonghua liu xing bing xue za zhi. 2017;38(6):721-6.

25. Su J, Zhang Y, Wang P, Du J, Wei Z. Comparative analysis of comprehensive health status between 31 provinces and 134 countries (regions) in China in 2015. Chinese J Prev Med. 2020;54(02):165-8.

26. Tianyi Wu M, Shupin Li M, Michal P. Ward MJW, Medicine E: Tibetans at Extreme Altitude 2005, 16(1):p.47-54.

27. Zhao X, Hong F, Yin J, Tang W, Zhang G, Liang X, Li J, Cui C, Li X: Cohort profile: the China Multi-Ethnic cohort (CMEC) study. Int J Epidemiol. 2020(prepublish).

28. Du H, Bennett D, Li L, Whitlock G, Guo Y, Collins R, Chen J, Bian Z, Hong LS, Feng $\mathrm{S}$, et al. Physical activity and sedentary leisure time and their associations with BMI, waist circumference, and percentage body fat in 0.5 million adults: the China Kadoorie biobank study. Am J Clin Nutr. 2013;97(3): 487-96.

29. Gong W, Liu A, Yao Y, Ma Y, Ding C, Song C, Yuan F, Zhang Y, Feng G, Chen $Z$, et al. Nutrient supplement use among the Chinese population: a cross-sectional study of the 2010(-)2012 China Nutrition and Health Surveillance. Nutrients. 2018;10(11):1733.

30. Pan XB, Wang HJ, Zhang B, Liu YL, Qi SF, Tian QB. Plain water intake and association with the risk of overweight in the Chinese adult population: China health and nutrition survey 2006-2011. Epidemiol. 2020;30(3):128-35.

31. Parna K, Ringmets I, Siida S. Self-rated health and smoking among physicians and general population with higher education in Estonia: results from cross-sectional studies in 2002 and 2014. Arch Public Health. 2019;77:49.

32. Hirshkowitz M, Whiton K, Albert SM, Alessi C, Bruni O, DonCarlos L, Hazen N, Herman J, Katz ES, Kheirandish-Gozal L, et al. National Sleep Foundation's sleep time duration recommendations: methodology and results summary. Sleep Health. 2015;1(1):40-3.

33. Kim JH, Kim KR, Cho KH, Yoo KB, Kwon JA, Park EC. The association between sleep duration and self-rated health in the Korean general population. Clin Sleep Med. 2013;9(10):1057-64

34. Shankar A, Charumathi S, Kalidindi S. Sleep duration and self-rated health: the Natiional health interview survey 2008. Sleep. 2011;34(9):1173-7.

35. Kroenke K, Spitzer RL, Williams JBW. The patient health questionnaire-2: validity of a two-item depression screener[J]. Med Care. 2003;41(11):1284-92.

36. Yeung A, Fung F, Yu S-C, Vorono S, Ly M, Wu S, Fava M. Validation of the patient health questionnaire-9 for depression screening among Chinese Americans. Compr Psychiatry. 2008;49(2):211-7.

37. Liu ZW, Yu Y, Hu M, Liu HM, Zhou L, Xiao SY. PHQ-9 and PHQ-2 for screening depression in Chinese rural elderly. PLoS One. 2016;11(3): e0151042.

38. Donker T, Straten Av, Marks I, Cuijpers P. Quick and easy self-rating of Generalized Anxiety Disorder: Validity of the Dutch web-based GAD-7, GAD2 and GAD-SI. Psychiatry Res. 2011;188(1):58-64.

39. Taylor JAJJAP. A personality scale of manifest anxiety. J Abnormal Psychol. 1953;48(2):285-90.

40. Seo J-G, Park S-P. Validation of the Generalized Anxiety Disorder-7 (GAD-7) and GAD-2 in patients with migraine. J Headache Pain. 2015;16(1):97.

41. Wang Y. Predictive values of body mass index and waist circumference for risk factors of certain related diseases in Chinese adults-study on optimal cut-off points of body mass index and waist circumference in Chinese adults. Biomed Environ Sci. 2002;15(1):83-96.

42. $\mathrm{N} \mathrm{A}$. Closing the gap in a generation: Health equity through action on the social determinants of health. Proceedings of an international conference based on the work of the Commission on Social Determinants of Health, 6 7 November 2008, London, UK. Glob Health Promot. 2009;6(Suppl 1):1-118.

43. Hanibuchi T, Nakaya T. Associations of neighborhood socioeconomic conditions with self-rated health, mental distress, and health behaviors: a nationwide cross-sectional study in Japan. Prev Med Rep. 2020;18:101075.

44. Hu A, Hibel J. Educational attainment and self-rated health in contemporary China: A survey-based study in 2010. Soc Sci J. 2013;50(4):674-80.

45. Emilie C, Sooyoung K, Song S, Yu W, Peter M. Can social solicies smprove health? A systematic review and meta-analysis of 38 randomized trials. Milbank Q. 2020;98(2):12451.

46. Qin X, Pan J, Liu GG. Does participating in health insurance benefit the migrant workers in China? An empirical investigation. China Econ Rev. 2014;30:263-78.

47. Meyer CP, Allard CB, Sammon JD, Hanske J, McNabb-Baltar J, Goldberg JE, Reznor G, Lipsitz SR, Choueiri TK, Nguyen PL, et al. The impact of Medicare eligibility on cancer screening behaviors. Prev Med. 2016:85:47-52.

48. Amy F, Sarah T, Bill W, Mira B, Jonathan G, Joseph PN, Heidi A, Katherine B, Oregon Health Study Group: THE OREGON HEALTH INSURANCE EXPERIMENT: EVIDENCE FROM THE FIRST YEAR. Q J Econ. 2012;127(3):1057.

49. Liu J, Chen H, Chen Y, Li Z. Exploring the relationship between migrants' purchasing of commercial medical insurance and urbanisation in China. BMC Health Serv Res. 2018;18(1):679.

50. Xue Y, Liu G, Geng Q. Associations of cardiovascular disease and depression with memory related disease: a Chinese national prospective cohort study. J Affect Disord. 2020;266:187-93.

51. Kumar S, Pradhan MR. Self-rated health status and its correlates among the elderly in India. J Public Health. 2019;27(3):291-9. 
52. Zadworna M. Healthy aging and the University of the Third age - health behavior and subjective health outcomes in older adults. Arch Gerontol Geriatr. 2020;90:104126.

53. Yeo SC, Jos AM, Erwin C, Lee SM, Lee XK, Lo JC, Chee MWL, Gooley JJ. Associations of sleep duration on school nights with self-rated health, overweight, and depression symptoms in adolescents: problems and possible solutions. Sleep Med. 2019;60:96-108.

54. Frisher M, Mendonça M, Shelton N, Pikhart H, Oliveira Cd, Holdsworth C. Is alcohol consumption in older adults associated with poor self-rated health? Cross-sectional and longitudinal analyses from the English Longitudinal Study of Ageing. BMC Public Health. 2015;15(1):703.

55. Dieteren CM, Brouwer WBF, Exel Jv. How do combinations of unhealthy behaviors relate to attitudinal factors and subjective health among the adult population in the Netherlands? BMC Public Health. 2020;20:1808.

56. Pärna K, Ringmets I, Siida S. Self-rated health and smoking among physicians and general population with higher education in Estonia: results from crosssectional studies in 2002 and 2014. Arch Public Health 2019;77(6):49.

57. Adams J, Nettle D. Time perspective, personality and smoking, body mass, and physical activity: an empirical study. Br J Health Psychol. 2009;14:83-105.

58. Johansson LM, Lingfors $H$, Golsäter M, Kristenson M, Fransson El. Can physical activity compensate for low socioeconomic status with regard to poor self-rated health and low quality-of-life? BioMed Central. 2019:17(1):33,

59. Sun S, Guo Y, Ruan Y, Zheng Y, Huang Z, Shi Y, Wu F. Association between quality of life and physical activity in people aged 50 and over. Chin $J$ Epidemio. 2019:40(10):1245-51.

60. Jylhä M. What is self-rated health and why does it predict mortality? Towards a unified conceptual model. Soc Sci Med. 2009;69(3):307-16.

61. Chan YY, Teh CH, Lim KK, Lim KH, Yeo PS, Kee CC, Omar MA, Ahmad NA. Lifestyle, chronic diseases and self-rated health among Malaysian adults: results from the 2011 National Health and morbidity survey (NHMS). BMC Public Health. 2015;15(1):754.

62. Levola, Eskelinen, Pitkänen. Associations between self-rated health, quality of life and symptoms of depression among Finnish inpatients with alcohol and substance use disorders. J Substance Use. 2020;25(2):128-34.

63. Breidablik H-J. Self-rated health in adolescence: A multifactorial composite. Scand J Public Health. 2008;36(1):12-20.

64. Zunzunegui MV, Koné A, Johri M, Béland F, Wolfson C, Bergman H. Social networks and self-rated health in two French-speaking Canadian community dwelling populations over 65. Soc Sci Med. 2004;58(10):2069-81.

\section{Publisher's Note}

Springer Nature remains neutral with regard to jurisdictional claims in published maps and institutional affiliations.

Ready to submit your research? Choose BMC and benefit from:

- fast, convenient online submission

- thorough peer review by experienced researchers in your field

- rapid publication on acceptance

- support for research data, including large and complex data types

- gold Open Access which fosters wider collaboration and increased citations

- maximum visibility for your research: over $100 \mathrm{M}$ website views per year

At $\mathrm{BMC}$, research is always in progress.

Learn more biomedcentral.com/submissions 